\title{
Promoting accountability with a new generation of logic models
}

Ann L. McCracken

\section{Abstract}

To better facilitate their work, program evaluators have developed a series of tools. One tool, the logic model, consists of inputs, activities, outputs, and outcomes. This article debates the adequacy of this commonly accepted logic model in evaluating the implementation of evidence-based practices in organizations. The author proposes a different logic model format which connects evidence and practice.

Keywords: Tools. Logic models. Evaluation.

\section{Resumo}

Promovendo credibilidade com uma nova

\section{Resumen}

Promoviendo credibilidad con una nueva generación de modelos lógicos

Los evaluadores de programas desarrollaron una serie de instrumentos para facilitar aún más sus trabajos. Un instrumento; el modelo lógico consiste de inputs, actividades, outputs y resultados.
Este artículo discute la adecuación de este modelo lógico comúnmente aceptado en la evaluación y en la implementación de prácticas basadas en la evidencia en las organizaciones. El Director of Evaluation - The Health Foundation of Greater Cincinnati amccracken@healthfoundation.org

\section{geração de modelos lógicos.}

Os avaliadores de programas desenvolveram uma série de instrumentos para facilitar mais os seus trabalhos. Um instrumento; o modelo lógico consiste de inputs, atividades, outputs e resultados. Este artigo discute a adequação deste modelo lógico comumente aceito na avaliação e na implementação de práticas baseadas na evidência nas organizações. $\bigcirc$ autor propõe o formato de um modelo lógico diferente que conecta a evidência prática.

Palavras-chave: Instrumentos. Modelos lógicos. Avaliação. autor propone el formato de un modelo lógico diferente que conecta la evidencia práctica.

Palavras clave: Instrumentos. Modelos lógicos. Evaluación

\section{A brief history of logic model development}

In an attempt to improve program implementation, international development projects in the 1960s began to use the Logical Framework Approach (AUDIENCE DIALOGUE, 
2006). The World Bank was an early adopter of program evaluation and noted that "the logical framework is a methodology for conceptualizing projects and an analytic tool that has the power to communicate a complex project clearly and understandably on a single sheet of paper" (OPERATIONS POLICY DEPARTMENT, 1996, p.4). Furthermore, the World Bank stated that logical frameworks helped project designers and stakeholders:

- Set proper objectives.

- Define indicators of success.

- Identify key activity clusters (project components).

- Define critical assumptions on which the program is based.

- Identify means of verifying project accomplishments.

- Define resources required for implementation. (OPERATIONS POLICY DEPARTMENT, 1996, p.5)

In the 1980s, the logical framework, then called the logic model or program theory approach, filtered down to health and social welfare programs, which began to use logic modeling to direct programs (AUDIENCE DIALOGUE, 2006). In 1996, the United Way of America published Measuring Program Outcomes: A Practical Approach. The book specified inputs; activities; outputs; and initial, intermediate, and long term outcomes as the essential components of logic models. More recent models sometimes include a research component column, but research findings are not used consistently or effectively. The model, spread through the United Way network, was and remains problematic in at least three ways. First, there is no link between the program content and program science. Second, the logic model doesn't permit one to follow the "logic" of the program primarily because the components alternate between abstract and general, and concrete and specific. Third, the lo- gic model creates additional work because it is repetitious of the implementation plan and the process and outcome evaluations.

In 2000, the W. K. Kellogg Foundation published the Logic Model Development Guide. In this publication they looked at logic models that were useful to foundations and others. The Kellogg Foundation supported the activities and the outcomes approaches to logic models that appeared in the United Way of America publication. However, they further expanded the rational aspect of the logic model in the Theory-of-Change logic model. The Theory-of-Change logic model was quite familiar to academics but not nearly as familiar to staff who were planning and evaluating programs in community agencies. The Kellogg Foundation included problem or issue, community needs/assets, and desired results (outputs, outcomes, and impact) in the program planning model. However, when the real work of creating a logic model to frame the evaluation questions was completed, the Kellogg Foundation logic model looked very much like the United Way of America model.

Conspicuously absent from the very similar World Bank, United Way, and Kellogg Foundation designs were the connections between the program science, the program operations, and expected outcomes. This author posits that the value of the logic model lies in illustrating these connections.

Given the explosion of accessible information and the push for accountability, programs are increasingly guided by evidence-based practices. Evidence-based practices have already demonstrated efficacy in rigorous basic and applied research. There is no reason to replicate this costly research. However, the logic model has great potential in illustrating the program's 
adherence to the evidence-based practice. In addition, the logic model is an opportunity to address the context for the program implementation and the sustainability of the program.

\section{Program Implementation Evaluation: one Foundation's experience}

In 1998, The Health Foundation of Greater Cincinnati hired this author as the a fulltime Director of Evaluation about one year after the Foundation began. In this role, the author, explored existing approaches such as the United Way and the Kellogg Foundation's work on program evaluation. To this author, the untapped potential of the logic model lies within its ability to be a systematic and visual representation of the relationships between program implementation and its scientific underpinnings, which existing logic models missed. As I began to work with grantees, I found myself asking a set of common questions to better understand the logic of their proposed programs. These questions included:

- What was the problem that led to the belief that this program was needed?

- What evidence-based practices will resolve this problem?

- What will the solved problem look like?

- What does research say must be done to carry out and keep the intervention in place?

- Once the intervention is in place, what outcomes can be expected according to the research?

The answers to these questions resulted in a visual representation of the program that both the funded agency and the funder could "see" in a diagram on a single sheet of paper. The connection between practice and research became apparent. The visual representation became the program logic model (see Figure 1).

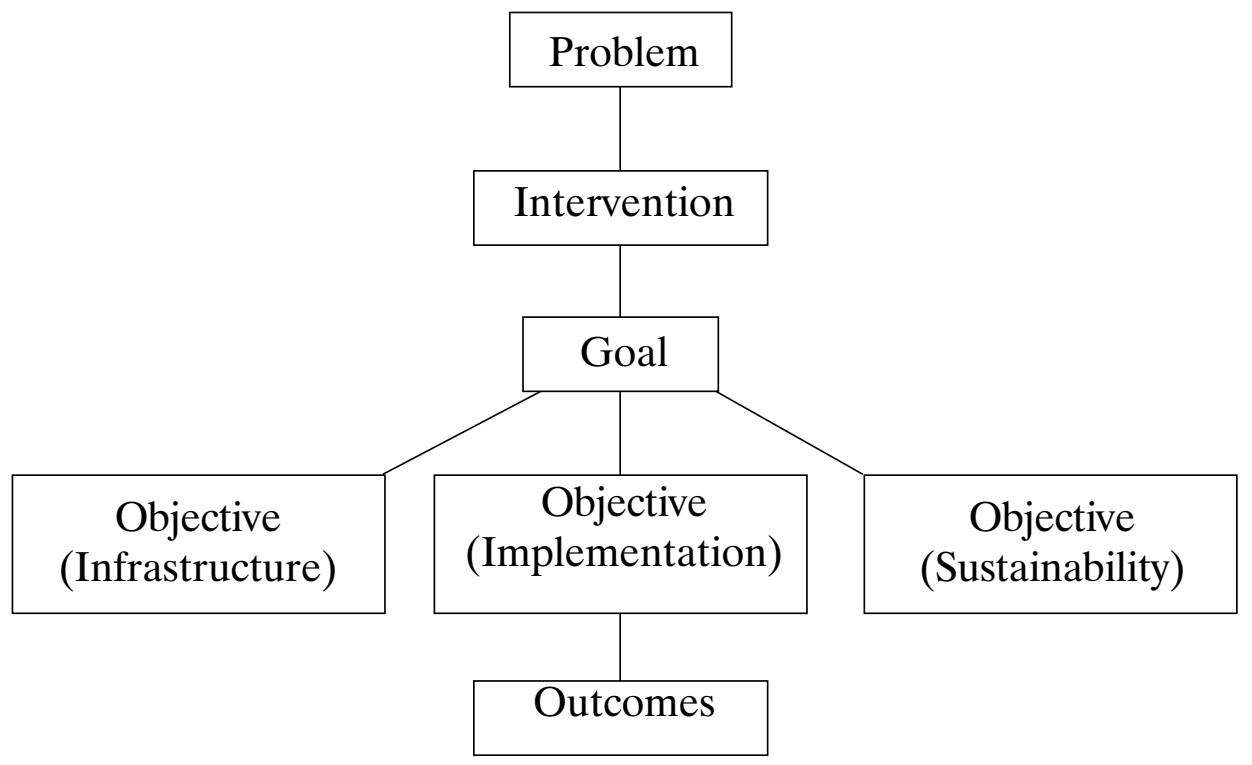

Figure 1 - Logic Model 


\section{The Problem}

\section{What was the problem that led to the} belief that this program was needed?

The first item on the agenda is to carefully define the person-centered problem that is being addressed. The problem is not that the organization does not have a given program; the problem is the deleterious things that happen to people because they do not have access to a given program. A good problem description assists both the funder and the grantee in knowing if the problem falls within their respective missions and if knowledge exists to solve the problem. It identifies the target population and the context of practice.

\section{The Intervention}

\section{What evidenced-base practices will resolve this problem?}

Next, an intervention is chosen to solve the problem. Both the grantee and the funder can ask if the identified problem can be solved with the proposed intervention and if the target population resembles the evidence-based practice's study subjects. Based on literature, they will also know the activities that are necessary to carry out the intervention, the outcomes that they can expect, and the benchmarks for the percent of clients who can be expected to achieve the outcomes.

\section{The Goal}

\section{What will the solved problem look like?}

The goal statement is simply the problem solved by the intervention. Most program goals are person-centered and general enough to encompass all of the specified outcomes. The outcomes are indications that the grantee has achieved the goal.

\section{The Objectives}

\section{What does research say must be done to carry out and keep the intervention in place?}

The objectives are general categories of the work necessary to carry out and keep the intervention in place. The activities necessary to accomplish the objectives are specified in the process evaluation, not in the logic model. The actions are derived from the evidence-based practice selected, theories of action and change, practice knowledge, contextual factors, and sustainability considerations. The objectives tend to fall into three main categories:

- getting the infrastructure in place to thoroughly ground the program,

- implementing the intervention, and

- sustaining the intervention over time.

\section{The Outcomes}

\section{Once the intervention is in place, what outcomes can be expected according to the research?}

The expected outcomes are identified in the evidence-based practice literature. Congruence is checked with other parts of the logic model. The outcomes are:

- the problem solved,

- an appropriate expectation given the intervention,

- ways to measure the goal, and

- the expected results of the objectives.

\section{Logic Model Example}

The following is a simplified example of the creation of a logic model for the implementation of a Program of Assertive Community Treatment for people with severe mental illness. See Figure 2 for the completed logic model. 


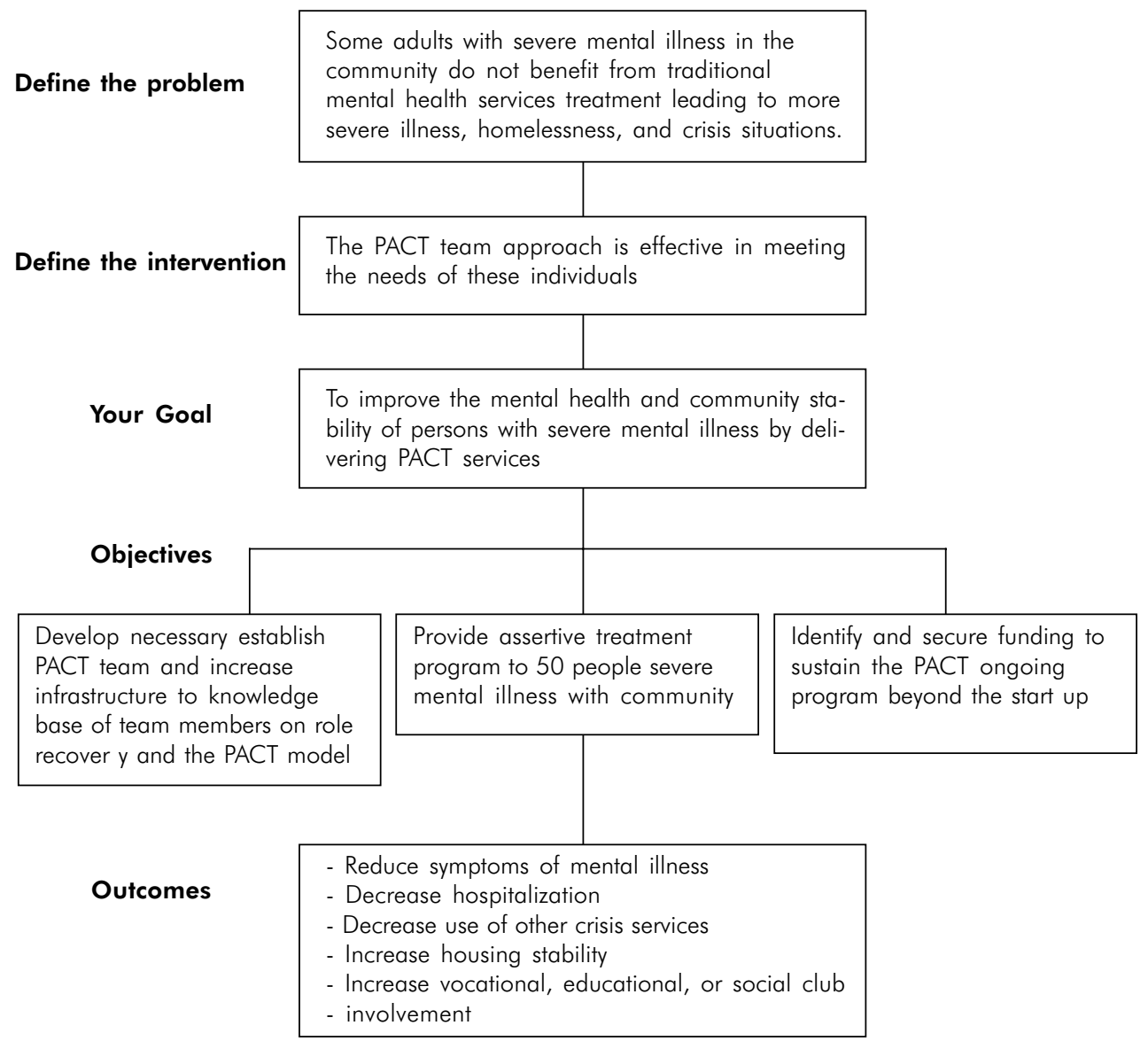

Figure 2

Logic Model Example

The Problem: What was the problem that led to the belief that this program was needed?

The closing of most mental hospitals in the United States resulted in many people with severe mental illnesses residing in the community. Intensive mental health services for people with severe mentally illnesses did not accompany these people into the community. As a result, their treatment is often inadequate, leading to an exa- cerbation of signs and symptoms of illness, homelessness, and the use of crisis services for care.

The Intervention: What evidenced-based practices will resolve this problem?

The Program of Assertive Community Treatment (PACT) provides comprehensive community-based treatment to people with severe and persistent mental illness (ALLNESS; KNOEDLER, 1999). 
The Objectives: what does research say must be done to carry out and keep the intervention in place?

The PACT team (psychiatric nurse, psychiatrist, mental health professionals, social worker, substance abuse counselor, and vocational specialist) provides intensive treatment, rehabilitation, and support services to clients in their homes, on the job, and in social settings (ALLNESS; KNOEDLER, 1999). "Issues that should be considered [when implementing PACT] include adequate funding, monitoring of fidelity, adaptation of policies and procedures to accommodate the model, and adequate training of professional staff." (PHILLIPS et al., 2001, p. 778).

\section{The Outcomes: once the intervention is in place, what outcomes can be ex- pected according to the research?}

In a review of more than 25 clinical trials, authors noted that assertive community treatment, "reduces hospitalization, increases housing stability, and improves the quality of life for those individuals who experience the most intractable symptoms and experience the greatest impairment as a result of mental illness" (PHILLIPS et al., 2001, p. 778).

\section{Use of the Logic Model and the cor- responding evaluation}

The one-page logic model forms the framework for both the process and outcome evaluations. The process and outcome evaluations specify inputs, activities (performance targets), and outcomes within specified timelines. The goal, objectives, and outcomes become a part of the contract signed by the Health Foundation and the grantee thus establishing clarity and consensus of expectations.

The Health Foundation recognizes that its mission "to improve the health of the people of the Cincinnati region" is accomplished through a partnership with grantees. In addition to supplying the money for the work, the Health Foundation is instrumental in non-profit capacity building. Grantees are asked to review evaluation data quarterly and notify the Health Foundation when they encounter problems they are unable to solve. Frequently, grantees doing similar work encounter similar problems and the Health Foundation offers assistance or engages consultants to assist grantees. The grantee describes their success (or lack of) in achieving the objectives and outcomes in annual and final reports. Further details of the Health Foundation's capacity building activities, including the logic model and the evaluation process, can be found at www. healthfoundation.org under the heading "Non-profit Resources."

\section{Conclusion}

Using the combined wisdom of practitioners and foundation staff, The Health Foundation of Greater Cincinnati designed a logic model and an accompanying process and outcome evaluation. The Health Foundation has used this logic model for nearly 7 years, tweaking it from time to time based on grantee feedback. The logic model facilitates discussion of the program and its theoretical base in a clear and concise way, promotes fidelity in implementation, assists in thinking about the realistic expectations of the program, and serves as a focal point for unification of all stakeholders. The logic model is the link between the evidence-based practice and the service delivery program. It is central in understanding the credibility of proposed programs. For both the grantee and funder, the logic model fosters accountability, transparen$c y$, and focus. In a world that expects accountability of public trusts, this new logic model format is an opportunity to depict investment in scientifically sound programs. 


\section{References}

ALLNESS, D. J.; KNOEDLER, W. H. The PACT model of community-based treatment for persons with severe and persistent mental illnesses. Arlington, VA.:NAMI, 1999.

AUDIENCE DIALOGUE. Program logic: an introduction. Adelaide, South Australia, 2005. Disponível em: <http://www.audiencedialogue.org/proglog.html>.

Acesso em: 18 de maio de 2006.

OPERATIONS POLICY DEPARTMENT. Performance monitoring indicators a handbook for task managers. Washington, D.C.: World Bank, 1996.

PHILLIPS, S. D. et al. Moving assertive community treatment into standard practice.

Psychiatric Services, Stanford, Calif., n. 52, p. 771-779, 2001.

UNITED WAY OF AMERICA. Measuring program outcomes: a practical approach. Alexandria, VA, 1996.

W.K. KELLOGG FOUNDATION. Logic model development guide. Battle Creek, Michigan, 2000.sss

Recebido: 31/10/2006

Aceito para publicação: 08/11/2006 